\title{
The effect of meal size on the cardiovascular responses to food ingestion
}

\author{
BY MICHAEL B. SIDERY AND IAN A. MACDONALD \\ Department of Physiology and Pharmacology, University of Nottingham Medical School, \\ Clifton Boulevard, Nottingham NG7 $2 \mathrm{UH}$
}

(Received 23 July 1993 - Revised 15 September 1993 - Accepted 23 September 1993)

\begin{abstract}
Cardiac output (CO; indirect Fick), blood pressure (BP) and heart rate (HR; oscillometry), superior mesenteric artery blood flow (SMABF; Duplex Doppler) and calf blood flow (CBF; venous occlusion plethysmography) were recorded in the fasted state and for 120 min following the ingestion of 1,2 , and $3 \mathrm{MJ}$, high-carbohydrate meals in eight healthy females. BP was unchanged following food. HR $(P<0.0005)$ and $\mathrm{CO}(P<0.005)$ rose significantly following all three meals. Integrated increments in $\mathrm{CO}$ over the postprandial period were greater after $3 \mathrm{MJ}$ compared with the 1 and $2 \mathrm{MJ}$ meals $(P<0.05)$. SMABF rose significantly following all three meals. The pattern of blood flow response was significantly different between the 1 and $3 \mathrm{MJ}$ meals (interaction effect $P<0.02$, ANOVA), with blood flow after the $3 \mathrm{MJ}$ meal being significantly greater than flow after the $1 \mathrm{MJ}$ meal at 15, 60, and $90 \mathrm{~min}$. Similarly, the pattern of response was significantly different after the 2 and $3 \mathrm{MJ}$ meals (interaction effect $P<0.03$, ANOVA), with blood flow being significantly greater at 15 and $90 \mathrm{~min}$ after the $3 \mathrm{MJ}$ meal. CBF fell significantly in the first $15 \mathrm{~min}$ after the $3 \mathrm{MJ}$ meal and then recovered towards baseline values. No other significant changes in $\mathrm{CBF}$ were recorded. There are substantial peripheral and central cardiovascular changes after food in man and there appears to be a relationship between meal size and the extent of these changes.
\end{abstract}

Cardiac output: Blood flow: Meal size: High-carbohydrate meal

In the fasted, healthy subject, blood supply to the gastrointestinal tract accounts for a substantial proportion of the cardiac output (Donald, 1983). In the postprandial state blood flow to the mesenteric organs increases markedly from these fasted levels (Norryd et al. 1975; Moneta et al. 1988). Despite the mesenteric hyperaemia associated with food ingestion, cardiovascular homeostasis is maintained, with blood pressure in the young remaining unchanged (Kelbaek et al. 1989; Heseltine et al. 1990), whilst both heart rate and cardiac output increase (Gladstone, 1935; Waaler et al. 1990).

The pattern of the cardiovascular responses to food is partly dependent upon the composition of the meal (Qamar \& Read, 1988; Sidery et al. 1990). There is also a relationship between the postprandial increment in cardiac output and meal size, with a larger and more prolonged cardiac response following a large meal when compared with a small meal (Waaler et al. 1991). It was suggested that the greater increment in cardiac output following the larger meal is a consequence of a greater demand in the mesenteric bed.

The rate of absorption of nutrients in tissues following food ingestion is a function of the blood flow to those vascular beds (Laakso et al. 1990). The functional advantages of a rapid nutrient delivery to the periphery following absorption from the gut are clear and an increased cardiac output would facilitate this process. The aim of the present investigation 
was to study the effect of meals of differing energy content but constant fat: carbohydrate ratio on superior mesenteric artery blood flow, cardiac output and blood flow in skeletal muscle, using the calf as a muscle bed. Sampling of arterialized venous blood allows simultaneous measurements of plasma insulin and whole-blood glucose. Samples were also stored for noradrenaline analysis. Although there are limitations in the degree to which plasma noradrenaline levels reflect sympathetic nervous system activity (Esler et al. 1988), there is a surprisingly good correlation between such measurements and the activity of the sympathetic nervous system assessed by recording sympathetic nerve firing in the leg (Wallin et al. 1981).

\section{METHODS}

Eight healthy female subjects (body mass index (BMI) $21 \cdot 3-25 \cdot 2 \mathrm{~kg} / \mathrm{m}^{2}$, age range $21-26$ years) were recruited for the study. None were taking any medication other than the oral contraceptive pill. All gave written informed consent to the study which was approved by the University of Nottingham Medical School Ethics Committee.

On three occasions, following an overnight fast of 10 to $15 \mathrm{~h}$ duration, the subjects were studied supine in a temperature-controlled room (dry bulb $26 \pm 2^{\circ}$ ). On arrival in the laboratory, subjects rested supine for $30 \mathrm{~min}$, during which time the monitoring equipment was attached and a cannula for blood sampling inserted retrogradely under local anaesthetic into a vein on the dorsum of the right hand. The cannula was kept patent with a slow infusion of $154 \mathrm{~mm}-\mathrm{NaCl}$ and the hand rested in a box circulated with warm air $\left(55-60^{\circ}\right)$ to obtain 'arterialized' venous blood samples. The total volume of saline infused did not exceed $350 \mathrm{ml}$ on each occasion. The arterialization of venous blood for the estimation of arterial blood glucose levels has been validated previously (McGuire et al. 1976). Heating of the hand leads to a reduction in the transit time and thus minimizes the extraction of glucose by the hand tissue, providing a realistic alternative to arterial sampling. This method of hand heating does not affect body temperature or forearm blood flow on the other side (Gallen \& Macdonald, 1990) but as yet it is not known whether this method provides accurate estimation of arterial plasma catecholamine levels.

Following the rest period two sets of measurements of all variables were made at $15 \mathrm{~min}$ intervals. Following this the subjects sat up and ate (no longer than 15 min was taken to complete the meals in all cases), in a randomized order, a standardized high-carbohydrate meal containing either 1, 2, or $3 \mathrm{MJ}$ (approximately $84 \%$ energy from carbohydrate; see Table 1). Subjects immediately returned to the supine position and measurements were made at 15 and 30 min after completion of the meal and subsequently at 30 min intervals for another $90 \mathrm{~min}$ (a total of $120 \mathrm{~min}$ postprandially). Blood samples were taken at $30 \mathrm{~min}$ intervals. At least 1 week passed between each visit. Volume occupied by the meals did differ, with the $1 \mathrm{MJ}$ meal being approximately $350 \mathrm{ml}$, the $2 \mathrm{MJ}$ meal $520 \mathrm{ml}$ and the $3 \mathrm{MJ}$ meal $585 \mathrm{ml}$. The observers measuring blood pressure, cardiac output and limb blood flow were blinded as to the energy content of the meals.

The subjects were also studied on a fourth occasion, in which the same protocol was followed, except that $580 \mathrm{ml}$ water at room temperature was ingested following the baseline period. No blood samples were taken and post-water measurements were made every $15 \mathrm{~min}$ for $45 \mathrm{~min}$ only. In addition, superior mesenteric artery blood flow was measured 5 min after water ingestion.

Cardiac output was measured using the indirect Fick principle, monitoring respiratory gases with $\mathrm{CO}_{2}$ as an indicator. The subjects were attached to the breathing equipment using a mouthpiece and wearing a nose-clip. $\mathrm{CO}_{2}$ concentrations were measured using an infrared $\mathrm{CO}_{2}$ analyser (901 Mk 2; P. K. Morgan, Chatham, Kent). $\mathrm{CO}_{2}$ production was determined from measurements of ventilation rate (with a flowmeter) and mixed expired 
Table 1. Meal composition

\begin{tabular}{cccc}
\hline & & \multicolumn{2}{c}{ Percentage energy from } \\
\cline { 3 - 4 } Meal size & Ingredients & Starch & Simple sugars \\
\hline 1 MJ & Cornflakes and skimmed milk & 54 & 29 \\
$2 \mathrm{MJ}$ & Cornflakes, skimmed milk, bread and honey & 48 & 36 \\
$3 \mathrm{MJ}$ & Cornflakes, skimmed milk, sugar, bread and honey & 43 & 44 \\
\hline
\end{tabular}

air. End-tidal $\mathrm{PCO}_{2}$ was used to estimate systemic arterial $\mathrm{CO}_{2}$ tension $\left(\mathrm{Pa}_{\mathrm{co}}\right)$ and mixed venous (pulmonary artery) $\mathrm{CO}_{2}$ tension $\left(\mathrm{P}_{\mathrm{CO}_{2}}\right)$ was determined with a $\mathrm{CO}_{2}$ rebreathing technique. The $\mathrm{CO}_{2}$ concentration in the rebreathing mixture was approximately $10 \%$. Rebreathing continues until there is no difference between expired and inspired $\mathrm{CO}_{2}$ concentration (approximately 8-10 s) measured at the mouthpiece. Cardiac output was calculated from the measurements of $\mathrm{Pi}_{\mathrm{CO}_{2}}$ and the estimated $\mathrm{Pa}_{\mathrm{CO}_{2}}$ and $\mathrm{P}_{\mathrm{CO}_{2}}$. This technique correlates well $(r 0.96,95 \%$ CI of the difference -0.37 to +0.47 litres $/ \mathrm{min})$ with cardiac output measurements made by thermodilution (Cowley et al. 1986). The validity of a $\mathrm{CO}_{2}$ rebreathing method to determine cardiac output, particularly at rest, has been questioned (Reybrouck \& Fagard, 1990). However, in that case the method used involved an exponential-based estimation of $\mathrm{P}_{\mathrm{CO}_{2}}$. The equilibrium method used in the present study to measure $P \bar{v}_{\mathrm{CO}_{2}}$ appears to be more reliable, showing closer agreement than the exponential method with cardiac output measured using both the direct Fick (Muiesan et al. 1968) and dye dilution (Hinderliter et al. 1987) techniques. The reproducibility of $\mathrm{P} \overline{\mathrm{V}}_{\mathrm{CO}}$ measurement by the equilibrium method was also shown to be excellent (Muiesan et al. 1968).

Time-integrated increases in cardiac output over the postprandial period were also calculated. The cardiac output increments above baseline for the first $15 \mathrm{~min}$ period and the subsequent 30, 60, 90 and 120 min measurements were calculated and the total extra blood volume pumped by the heart over each time period and for each subject calculated from these cardiac outputs and expressed in litres with the standard error of the mean.

Heart rate and systemic arterial blood pressure were measured by an automated oscillometric device (Accutorr 1A; Datascope, Paramus, NJ, USA) with the cuff placed around the right upper arm. Measurements were made once every $5 \mathrm{~min}$ and the mean of three measurements was calculated for the $15 \mathrm{~min}$ time windows; the mean of six was calculated for each of the $30 \mathrm{~min}$ time windows. The coefficient of variation of repeated measurements in fasted subjects using this technique in this laboratory is $4 \%$ for heart rate, $2 \%$ for systolic blood pressure and $2 \%$ for diastolic blood pressure.

Superior mesenteric artery (SMA) flow was measured by transcutaneous Doppler ultrasound (Diasonics Prisma; Diasonics International, Les Vlis, France) with a convex linear array probe with variable receiver characteristics. The B-mode imaging system operates with a centre frequency of $3.5 \mathrm{MHz}$. Doppler frequency of the probe is $3 \mathrm{MHz}$. The anatomical position of the SMA makes visualization of the proximal part of the vessel using ultrasound comparatively easy. Complete data on SMA flow for all three occasions were obtained in seven of the eight subjects.

The vessel of interest was visualized with a sagittal scan of the abdomen. Care was taken to ensure that the entire vessel lumen was insonated and the sample volume was placed in the proximal part of the artery, several centimetres from the bifurcation of the SMA from 
the aorta. This avoids the introduction of error in flow measurements as a result of turbulent flow which may be present near the junction of the two arteries.

The angle of insonation was recorded and used to convert the Doppler Shift values $(\mathrm{kHz})$ into blood flow velocity $(\mathrm{cm} / \mathrm{s})$. Care was taken to ensure that wherever possible the same angle of insonation was used in each individual (mean angle of insonation was $39^{\circ}$, SD $3.5^{\circ}$ ). Error brought into the flow calculation due to an angle of insonation of $39^{\circ}$ would be in the range of $7 \%$ (Gill, 1985). Recordings were made with the subjects' breath held in mid inspiration and mean values of time-averaged velocity (TAV) were taken from at least eight Doppler waveform complexes. Using manually operated on-screen callipers systolic vessel diameter was measured during the baseline period of each study session. It was assumed that vessel diameter remained unchanged during the experimental protocol and the mean of the vessel diameter measurements for each subject was used with the TAV in the volume flow calculations. Blood flow was calculated from the equation:

$$
\text { blood flow }=3 \cdot 142 \times \mathrm{D}^{2} \times \mathrm{TAV} \times 60 / 4 \mathrm{ml} / \mathrm{min} \text {, }
$$

where $D$ is the vessel diameter.

A comparison of SMA flow measurement by Duplex ultrasound (calculated from the time-averaged flow velocities) and electromagnetic flowmetry has been made in which a strong correlation between the two techniques was found (Nakamura et al. 1989). The same paper reported a coefficient of variation in the measurement of volume flow very similar to our own.

Calf blood flow was measured by venous occlusion plethysmography (Greenfield et al. 1963) with mercury-in-silastic strain gauges (Whitney, 1953). An occlusion cuff placed around the thigh was inflated to $40 \mathrm{mmHg}$ to prevent venous return from the limb. Inflation took place in a cyclical manner, with the change in calf circumference being measured using the strain gauge. Flow both in and out of the foot was prevented during measurements using an occlusion cuff placed around the ankle and inflated to $200 \mathrm{mmHg}$. During each measurement period, a minimum of six measurements of flow were made and the mean value used in the subsequent statistical analysis. The coefficient of variation for measurement of calf blood flow by venous occlusion plethysmography on different days is $11.5 \%$ (Roberts et al. 1986). In our laboratory under resting conditions a $10 \%$ alteration in blood flow is the minimum change that can be detected using this technique.

Vascular resistances for the calf and the SMA were calculated from blood flow values and mean arterial blood pressure (obtained using the Accutorr 1A). For these calculations it was assumed that brachial artery pressure was a reliable index of calf and mesenteric perfusion pressures, although disparity between central and peripheral blood pressure measurements have been noted (Rowell et al. 1968). Any differences are likely to be minimized in healthy volunteers, and be similar on the three occasions.

Arterialized blood samples were used to measure blood glucose (YSI 23 AM; Yellow Springs Industries, Yellow Springs, OH, USA) immediately. The remainder of the arterialized blood samples were centrifuged and the plasma separated. Plasma $(3 \mathrm{ml})$ was mixed with $75 \mu \mathrm{l}$ EGTA-glutathione (antioxidant) and stored at $-80^{\circ}$ for later determination of noradrenaline and adrenaline concentrations using HPLC with electrochemical detection (Macdonald \& Lake, 1985). All samples for any one subject were run on the same day. The intra-assay coefficient of variation was $6 \%$ for noradrenaline and $8 \%$ for adrenaline, the inter-assay values being $8 \%$ and $10 \%$ at the levels of catecholamine present in these samples. Plasma was also stored at $-20^{\circ}$ for subsequent determination of insulin concentration by radioimmunoassay using a double-antibody technique developed in-house. The intra-assay coefficient of variation is $8 \%$ and the inter-assay value is $12 \%$ over a range of plasma insulin from 5 to $50 \mathrm{mU} / 1$. 


\section{Statistical analysis}

Statistical analysis of the results was performed by two-way analysis of variance with repeated measures (ANOVA) using the package BMDP (BMDP Statistical Software; Los Angeles, CA, USA). Where the ANOVA indicated a significant treatment--time interaction the exact level of significance at each time point was calculated using a paired $t$ test, using the variance term for the interaction from the ANOVA table, with a Bonferroni correction applied for multiple testing.

For clarity, data are presented in the Figures as changes from baseline, each point being the mean with its standard error. The data reported in the text on the responses to the meals are the maximum changes from baseline values, and the $95 \%$ confidence intervals $(\mathrm{CI})$ of the changes unless stated otherwise.

\section{RESULTS \\ Control study}

There were no significant changes in any of the measured variables following the ingestion of water.

\section{Systolic and diastolic blood pressure}

There was no difference in blood pressure in the fasted state on the three occasions. Neither systolic nor diastolic blood pressure changed significantly following any of the meals in these young subjects.

\section{Heart rate}

Heart rate rose significantly following all three meals $(P=0.00001)$, with a maximum rise of 5.9 beats $/ \mathrm{min}$ after the $1 \mathrm{MJ}$ meal ( $95 \%$ CI of the increase 2.4 to 9.4 beats $/ \mathrm{min}), 10.5$ beats/min after the $2 \mathrm{MJ}$ meal $(95 \% \mathrm{CI}$ of the increase 6.5 to 14.5 beats $/ \mathrm{min})$ and 13.3 beats $/ \mathrm{min}$ after the $3 \mathrm{MJ}$ meal $(95 \% \mathrm{CI}$ of the increase 8.8 to 17.8 beats $/ \mathrm{min})$. There was a significant difference in the pattern of response in heart rate following the 1 and $3 \mathrm{MJ}$ meals (interaction effect $P=0 \cdot 0005$, ANOVA; Fig. 1 ). Heart rate was significantly higher $15 \mathrm{~min}$ after the $3 \mathrm{MJ}$ compared with the $1 \mathrm{MJ}$ meal ( $t$ test with Bonferroni correction). There was no difference between the pattern of response after the 2 and $3 \mathrm{MJ}$ and the 1 and $2 \mathrm{MJ}$ meals. There was a significant difference in individual maximum increases in heart rates between the 1 and 2 MJ meals only ( $t$ test $P<0.05$; Fig. 2).

\section{Cardiac output}

Cardiac output rose significantly after all the meals $(P=0.0001)$. The maximum rise in cardiac output following the $1 \mathrm{MJ}$ meal was $2.19 \mathrm{l} / \mathrm{min}(95 \% \mathrm{CI}$ of the increase 0.96 to $3.42 \mathrm{l} / \mathrm{min}), 1.78 \mathrm{I} / \mathrm{min}$ after the $2 \mathrm{MJ}$ meal $(95 \% \mathrm{CI}$ of the increase 0.76 to $2.79 \mathrm{l} / \mathrm{min})$ and $3.15 \mathrm{l} / \mathrm{min}$ after the $3 \mathrm{MJ}$ meal $(95 \%$ CI of the increase 1.58 to $4.72 \mathrm{l} / \mathrm{min}$; Fig. 1). There was a significant difference between individual maximum increases in cardiac output between the 2 and $3 \mathrm{MJ}$ meals ( $t$ test $P=0.03$ ). The mean time-integrated postprandial increments in cardiac output after the three meals were $80 \cdot 1$ (SE 24.5), 104.1 (SE 42.2) and 244.0 (SE 49.7) 1 respectively, with the time-integrated cardiac output after the 3 MJ meal being significantly greater than after the $2 \mathrm{MJ}$ meal ( $t$ test $P=0.04$; Fig. 2).

\section{Total peripheral resistance $(T P R)$}

TPR fell significantly following all three meals $(95 \% \mathrm{CI}$ of the change $-3 \cdot 5$ to $-10 \cdot 7,-3 \cdot 3$ to $-17 \cdot 3$, and $-3 \cdot 1$ to -20.1 respectively). However, the pattern of responses was different, with TPR remaining low throughout the experimental period after the largest 

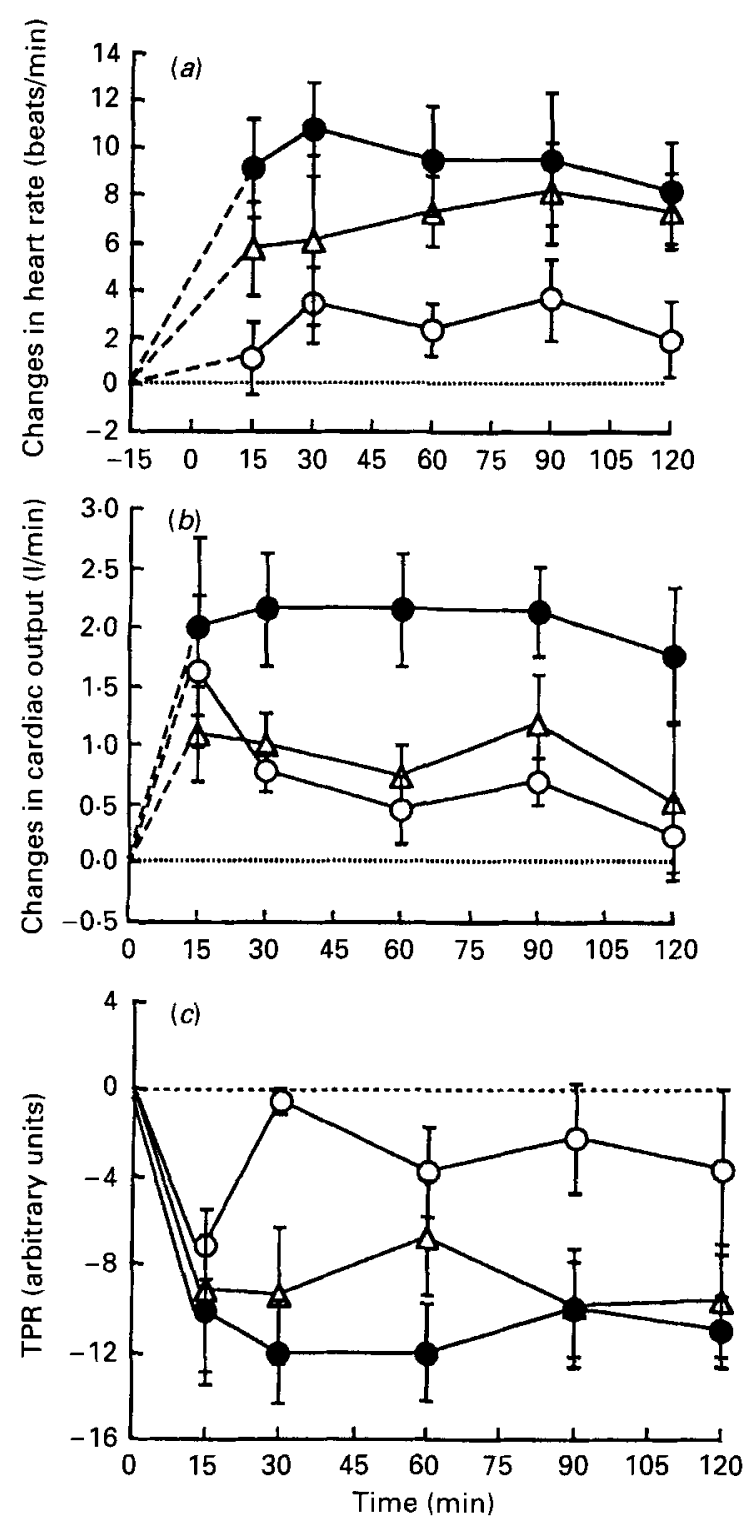

Fig. 1. Heart rate (beats $/ \mathrm{min} ; a)$, cardiac output $(1 / \mathrm{min} ; b)$ and total peripheral resistance (TPR; $)$ changes from baseline values (shown as a dotted line) following the ingestion of $1(O), 2(\triangle)$ and $3 \mathrm{MJ}(\boldsymbol{O})$ meals. Values are means with their standard errors represented by vertical lines. There was a significant rise in both heart rate and cardiac output following all the meals. TPR fell initially after all meals. The pattern of response was different between the largest and smallest meals for all three variables.

meal and recovering to values not significantly different from baseline values $30 \mathrm{~min}$ after the small meal (interaction effect $P=0 \cdot 02$, ANOVA; Fig. 1).

\section{SMA blood flow}

SMA flow rose significantly following all three meals, with a peak flow of $836 \mathrm{ml} / \mathrm{min}$ being reached at $15 \mathrm{~min}$ after the $1 \mathrm{MJ}$ meal $(95 \% \mathrm{CI}$ of the change 66 to $474 \mathrm{ml} / \mathrm{min})$, and a peak flow of $825 \mathrm{ml} / \mathrm{min}$ being reached at $60 \mathrm{~min}$ after the $2 \mathrm{MJ}$ meal $(95 \% \mathrm{CI}$ of the 

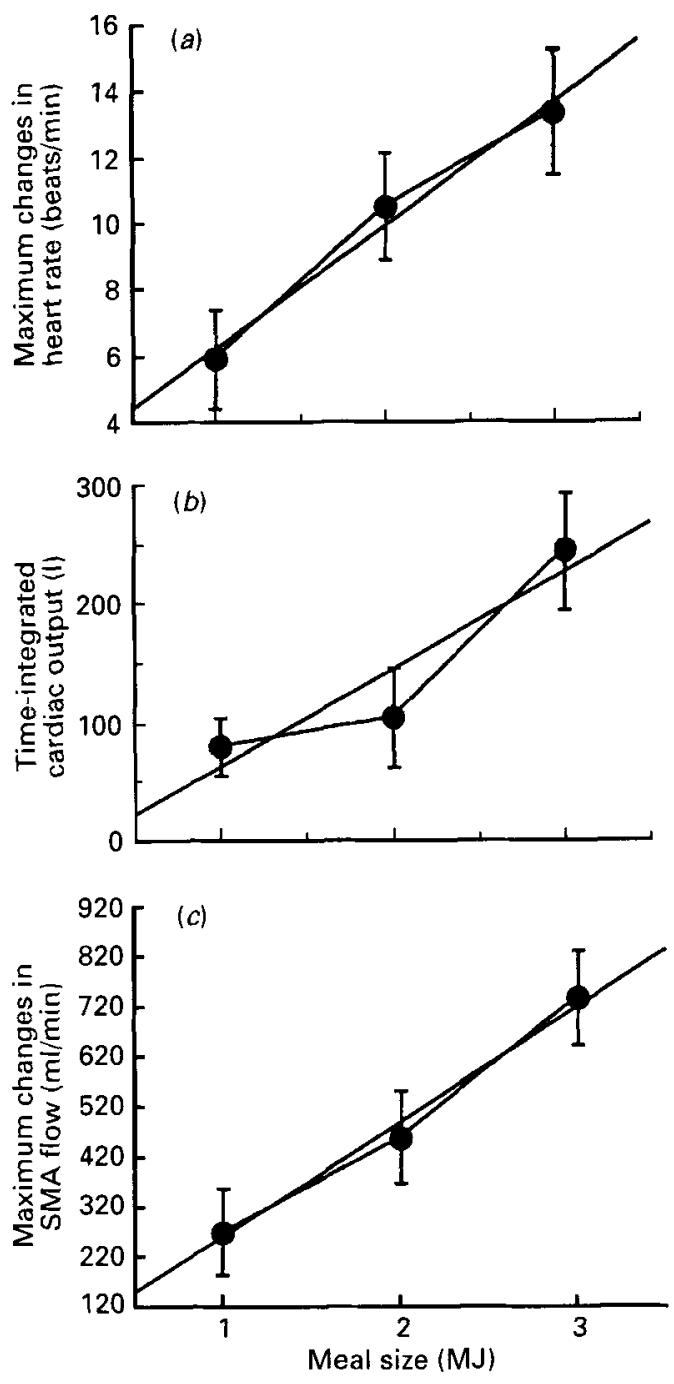

Fig. 2. Graphs showing the relationship between meal size (MJ) and $(a)$ the maximum increase in heart rate (beats $/ \mathrm{min}$ ), (b) the time-integrated increase in cardiac output above baseline (l) and $(c)$ the total blood flow above baseline through the superior mesenteric artery (SMA; $\mathrm{ml} / \mathrm{min}$ ). The maximum increase in heart rate after the 2 and $3 \mathrm{MJ}$ meals was significantly greater than after the $1 \mathrm{MJ}$ meal. The time-integrated increase in cardiac output was significantly greater after the 3 compared with the 1 and $2 \mathrm{MJ}$ meals. The total blood flow above baseline through the SMA was significantly greater after the 3 compared with the $1 \mathrm{MJ}$ meal only.

change 240 to $673 \mathrm{ml} / \mathrm{min}$ ). A peak flow of $1189 \mathrm{ml} / \mathrm{min}$ was reached $15 \mathrm{~min}$ after the $3 \mathrm{MJ}$ meal ( $95 \% \mathrm{CI}$ of the change 514 to $956 \mathrm{ml} / \mathrm{min}$ ). The pattern of blood flow response was significantly different between the 1 and $3 \mathrm{MJ}$ meals (interaction effect $P=0.01$, ANOVA), with blood flow after the $3 \mathrm{MJ}$ meal being significantly greater than flow after the $1 \mathrm{MJ}$ meal at 15,60, and 90 min ( $t$ test with Bonferroni correction at each time point). Similarly, the pattern of response was significantly different after the 2 and $3 \mathrm{MJ}$ meals (interaction effect $P=0.02$, ANOVA), with blood flow being significantly greater at 15 and $90 \mathrm{~min}$ after the $3 \mathrm{MJ}$ meal ( $t$ test with Bonferroni correction; Fig. 3). 

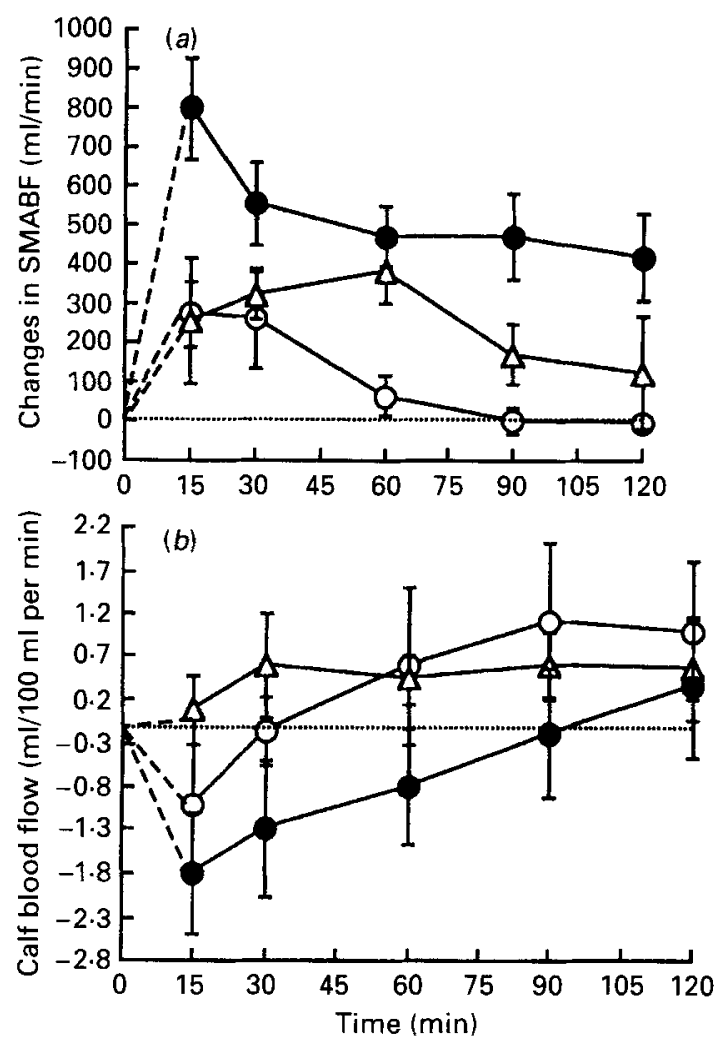

Fig. 3. Superior mesenteric artery blood flow (SMABF; $\mathrm{ml} / \mathrm{min} ; a)$ and calf blood flow $(\mathrm{ml} / 100 \mathrm{ml}$ per $\mathrm{min} ; b$ ) changes from baseline values (shown as a dotted line) following the ingestion of $1(O), 2(\triangle)$ and $3 \mathrm{MJ}(\mathrm{O})$ meals. Values are means with their standard errors represented by vertical lines. SMABF increased following all three meals. The pattern of response was different between the largest and smallest meals. Calf blood flow fell significantly following the $3 \mathrm{MJ}$ meal onjy. The rise in flow from the $15 \mathrm{~min}$ value to the value at $90 \mathrm{~min}$ after the $1 \mathrm{MJ}$ meal and $120 \mathrm{~min}$ after the $3 \mathrm{MJ}$ meal was significant.

The total volumes of blood flow above baseline in the postprandial period after the three meals were 12.1 (SE 5.9), 32.9 (SE 8.9) and 47.7 (SE 6.6) l. Total flow volume after the $3 \mathrm{MJ}$ meal was significantly greater than that after the $1 \mathrm{MJ}$ meal only $(t$ test $P=0.02$; Fig. 2 ).

\section{Peak flow velocity}

Peak flow velocity increased significantly following all three meals $(P<0.001)$. The maximum changes in peak flow velocity after the three meals were $42 \mathrm{~cm} / \mathrm{s}(95 \% \mathrm{CI}$ of the increase 15 to $69 \mathrm{~cm} / \mathrm{s}), 50 \mathrm{~cm} / \mathrm{s}(95 \%$ CI of the increase 29 to $71 \mathrm{~cm} / \mathrm{s})$ and $81 \mathrm{~cm} / \mathrm{s}(95 \%$ $\mathrm{CI}$ of the increase 63 to $99 \mathrm{~cm} / \mathrm{s}$ ) respectively. There was no significant difference in the pattern of flow velocity changes after the three meals.

\section{Calf blood flow}

Although calf blood flow tended to fall initially following all three meals, there was a significant fall in the first $15 \mathrm{~min}$ only after the $3 \mathrm{MJ}$ meal $(95 \% \mathrm{CI}$ of the change -0.36 to $-3.22 \mathrm{ml} / 100 \mathrm{ml}$ per $\mathrm{min}$ ). The trend was then for calf blood flow to rise, although flow did not rise above baseline after any of the meals during the experimental period. The rise from the $15 \mathrm{~min}$ calf blood flow value to the $120 \mathrm{~min}$ value following the $3 \mathrm{MJ}$ meal was 

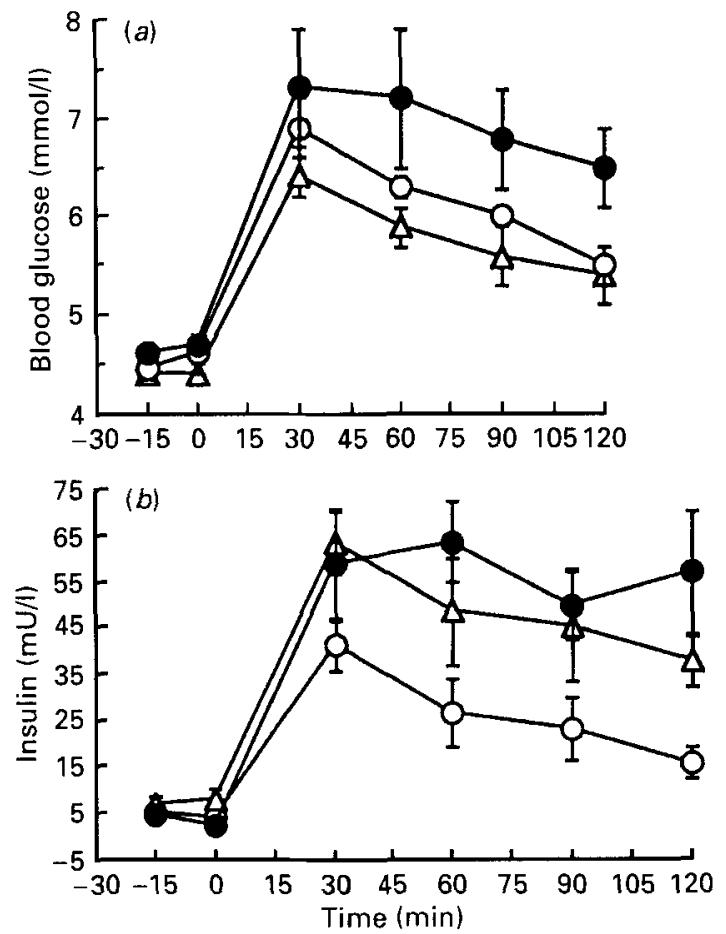

Fig. 4. Blood glucose $(a)$ and plasma insulin $(b)$ before $(t 0)$ and after the ingestion of $1(O), 2(\triangle)$ and $3 \mathrm{MJ}$ (C) meals. Values are means with their standard errors represented by vertical lines. There was a significant rise after all three meals. The pattern of response in blood glucose was significantly different between the $3 \mathrm{MJ}$ meal and the two smaller meals. The plasma insulin response was different between the 3 and $2 \mathrm{MJ}$ meals and the smallest meal. The area under the glucose curve was greater after the $3 \mathrm{MJ}$ meal compared with the $2 \mathrm{MJ}$ meal only.

significant $(95 \% \mathrm{CI}$ of the increase 0.27 to $3.97 \mathrm{ml} / 100 \mathrm{ml}$ per min). The rise from the $15 \mathrm{~min}$ value to the value at $90 \mathrm{~min}$ following the $1 \mathrm{MJ}$ meal was also significant $(95 \% \mathrm{CI}$ of the increase 0.5 to $3.78 \mathrm{ml} / 100 \mathrm{ml}$ per min; Fig. 3).

\section{Blood glucose}

Blood glucose rose significantly after all the meals $(P=0 \cdot 0001$, ANOVA). There was no significant difference between the peak blood glucose concentrations following any of the three meals. The areas under the glucose curves following the $2 \mathrm{MJ}$ and the $3 \mathrm{MJ}$ meals were significantly different ( $t$ test, $P=0 \cdot 001$ ). There was no difference between the 1 and 3 MJ meals (Fig. 4).

\section{Plasma insulin}

Plasma insulin concentrations rose significantly following the three meals $(P=0 \cdot 0001$, ANOVA). Again, there was no difference in the peak insulin response following any of the three meals. There was a difference in the pattern of response following the 1 and $3 \mathrm{MJ}$ meals (interaction effect $P=0 \cdot 002$, ANOVA; Fig. 4).

\section{Plasma noradrenaline and adrenaline}

Baseline plasma noradrenaline levels were 1.17 (SE 0.09), $1.30 \quad$ (SE 0.22) and 0.90 (SE 0.13) nmol/1 before the 1, 2 and $3 \mathrm{MJ}$ meals respectively. Plasma noradrenaline rose only after the $3 \mathrm{MJ}$ meal $(P=0.0001$, ANOVA), from a baseline value of 0.83 


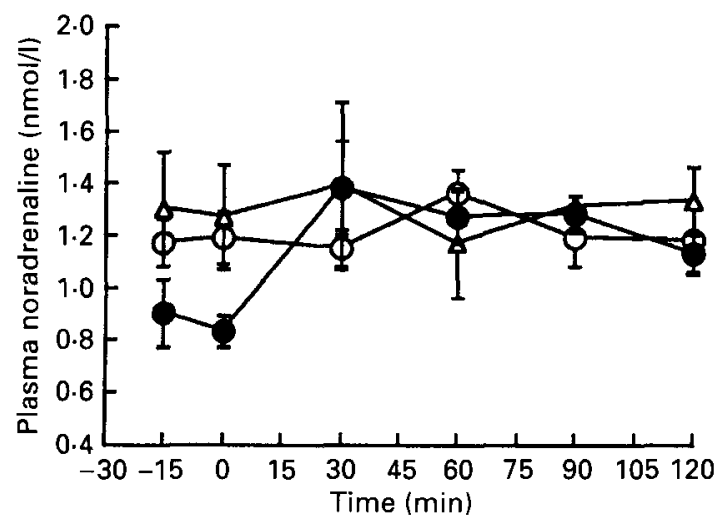

Fig. 5. Plasma noradrenaline changes from baseline values following the ingestion of $1(\mathrm{O}), 2(\triangle)$ and $3 \mathrm{MJ}(\odot)$ meals. Values are means with their standard errors represented by vertical lines. Plasma noradrenaline rose only after the $3 \mathrm{MJ}$ meal $(P<0.009$, ANOVA). This was the only time point at which plasma noradrenaline was significantly above baseline.

(SE 0.06) $\mathrm{nmol} / \mathrm{l}$ to 1.38 (SE 0.18$) \mathrm{nmol} / 115 \mathrm{~min}$ after the meal $(95 \%$ CI of the increase 0.07 to $1.03 \mathrm{nmol} / 1)$. This was the only time point at which plasma noradrenaline was significantly above baseline (Fig. 5).

Baseline plasma adrenaline levels were 0.20 (SE 0.03), 0.25 (SE 0.09) and 0.18 (SE 0.03) $\mathrm{nmol} / \mathrm{l}$ before the 1,2 and $3 \mathrm{MJ}$ meals respectively. Plasma adrenaline did not change after ingestion of any of the meals.

\section{DISCUSSION}

Cardiac output rose significantly following ingestion of all three high-carbohydrate meals. The increase was most rapid following the $1 \mathrm{MJ}$ meal, peaking at $15 \mathrm{~min}$. Cardiac output peaked between 30 and $60 \mathrm{~min}$ after the 2 and $3 \mathrm{MJ}$ meals. There is some variance as to the time at which the peak cardiac response is achieved following food ingestion (Fagan et al. 1986; Waaler et al. 1990, 1991), although meal composition appears to be important in the time course of these changes (Dagenais et al. 1966). The cardiac response after both the 1 and $2 \mathrm{MJ}$ meals is reflected in the mesenteric response, with both peaking at $15 \mathrm{~min}$ after the $1 \mathrm{MJ}$ and $60 \mathrm{~min}$ after the $2 \mathrm{MJ}$ meal. The time courses of the initial changes in cardiac output do not reflect the initial blood flow changes in the mesenteric bed following the $3 \mathrm{MJ}$ meal, when maximum hyperaemia in the mesentery was attained within the first 15 min and the cardiac output peak at about $60 \mathrm{~min}$. However, both cardiac output and mesenteric blood flow were maintained at elevated levels throughout the postprandial period after the $3 \mathrm{MJ}$ meal. Postprandial increases in stroke volume have been demonstrated previously (Kelbaek et al. 1987, 1989; Waaler et al. 1991) although not consistently (Fagan et al. 1986). Stroke volume and heart rate have been shown to contribute equally to the postprandial rise in cardiac output (Waaler et al. 1991). In the present study calculated stroke volume did increase significantly after all three meals. A fall in TPR may account for a fraction of the postprandial rise in stroke volume (by reducing afterload), but increases in stroke volume of $41 \%$ (Kelbaek et al. 1989) suggest a rise in pre-load and possibly in contractility of the heart. Thus, the exact mechanism of the increase in stroke volume is not clear either from the literature or from this study.

A 'dose-response' relationship exists between meal size and the total volume of blood pumped by the heart above baseline over a $2 \mathrm{~h}$ period (Waaler et al. 1991). The present study confirms and extends this relationship and also demonstrates that the same 
relationship exists between the meal size and both the maximum change in SMA flow and the total volume of blood flowing through the artery over a $120 \mathrm{~min}$ postprandial period.

Maximal hyperaemia was reached within $15 \mathrm{~min}$ after ingestion of two of the three meals. This rapid response following meals high in carbohydrate has been observed after both solid (Sidery et al. 1990) and liquid (Moneta et al. 1988; Qamar \& Read, 1988) carbohydrate meals. In the present study maximal flow following the intermediate meal was not reached until $60 \mathrm{~min}$ after food, but blood glucose levels peaked $30 \mathrm{~min}$ after food. A delayed hyperaemia has been observed after a high-fat meal which does not coincide with the peak blood glucose levels (Sidery et al. 1990). This observation, that peak blood glucose levels and peak mesenteric blood flow do not always coincide, is confirmation that the mechanisms mediating mesenteric blood flow are complex and not fully understood.

In the present study TPR fell following all three meals, with no difference in the extent of the fall. This is despite an increasingly greater initial hyperaemia with an increase in meal size. There was an initial fall in calf blood flow following the $3 \mathrm{MJ}$ meal only. Assuming that blood pressure measured at the upper arm reflects peripheral blood pressure, the recorded fall in blood flow in the calf is the result of increased vascular resistance: could this increase in resistance in the calf be responsible for the fact that values of TPR are no different after the meals, despite the significantly greater initial mesenteric response following the $3 \mathrm{MJ}$ meal? A postprandial increase in vascular resistance in vascular beds other than those associated with digestion and absorption has been demonstrated previously (Sidery et al. 1990). Skeletal muscle blood flow increased significantly following the initial fall after ingestion of the largest of the meals.

Blood glucose rose significantly following all three meals. There was a slight anomaly between the blood glucose response following the $1 \mathrm{MJ}$ and the intermediate size meal. Different glycaemic responses to meals of identical sugar, starch and energy contents but varying insoluble and soluble dietary fibre contents have been demonstrated (Torsdottir et al. 1989). The results of the present study may be a consequence of a difference in the nature of the carbohydrate in the 2 and $1 \mathrm{MJ}$ meals. Peak mesenteric blood flow was not reached until $60 \mathrm{~min}$ after the intermediate meal, in contrast to the other meals. This different pattern of response might also be related to carbohydrate type, and clearly warrants further study.

Plasma noradrenaline rose significantly following the largest of the three meals only. Increases in plasma noradrenaline have been observed in man following glucose ingestion (Rowe et al. 1979, 1981). Similarly, increases in sympathetic activity, detected using microelectrode recordings, have been shown following ingestion of glucose and xylose in man (Berne et al. 1989). A link between the increased plasma noradrenaline levels and the cardiovascular changes associated with food ingestion is not clear. There is a differential effect of meals of different composition on plasma catecholamines, with $120 \%(0.98$ to $2.22 \mathrm{nmol} / \mathrm{l})$ increases in plasma noradrenaline levels following a $2.4 \mathrm{MJ}$ highcarbohydrate meal and no changes after a high-fat meal of the same energy content (Heseltine et al. 1990).

To summarize, a 'dose-response' relationship between the cardiac and mesenteric response and the energy content of meals has been demonstrated. A similar relationship between cardiac output and meal size has been observed for meals ranging from approximately 2 to $5 \mathrm{MJ}$ (Waaler et al. 1991). There was a decrease in vascular resistance in the mesenteric bed after food and substantial increases in superior mesenteric blood flow were observed. The mechanism responsible for the substantial postprandial increments in cardiac output is not clear. TPR falls after food ingestion (Fagan et al. 1986; Kelbaek et al. 1989) and blood pressure remains either unaltered (Heseltine et al. 1990) or there is a slight widening of pulse pressure (de Mey et al. 1987) in young, healthy subjects. The 
cardiac changes seen in the postprandial state may in part be mediated by the autonomic nervous system. Unloading of peripheral baroreceptors would lead to increased activity of sympathetic cardiac fibres. Reduced atrial filling and distension would lead to increased vasomotor tone.

Deleterious effects of food ingestion are well documented in angina patients, with a significant reduction in exercise capacity and the time until depression of the ST segment of the electrocardiogram in the postprandial state compared with the fasted state (Fagan et al. 1982; Cowley et al. 1991). Similarly, there is a reduction in exercise tolerance in chronic heart failure patients after food ingestion (Muller et al. 1992). The mechanisms of these effects are unclear, but the evidence suggests that abnormal central and peripheral cardiovascular responses may be responsible. In angina the degree of myocardial ischaemia is the same during exercise in the pre- and postprandial states (Colles et al. 1993), lending credence to the hypothesis that increased postprandial myocardial oxygen consumption and not reduced coronary blood flow results in the earlier onset of ischaemic pain. Reduced exercise tolerance in heart failure is almost certainly due to abnormal peripheral blood flow responses. In view of this, food ingestion may act to exacerbate the already abnormal state in skeletal muscle during exercise.

Postprandial hypotension has been observed in both institutionalized elderly (Lipsitz et al. 1983) and also in healthy elderly subjects (Lipsitz \& Fullerton, 1986; Heseltine \& Potter, 1990). High-carbohydrate meals result in significantly greater falls in blood pressure compared with meals of any other composition (Potter et al. 1989). The mechanism for this is not clear. These subjects do not demonstrate significant cardiac responses to food ingestion, despite similar vascular changes in the mesenteric bed to those seen in the young (Sidery et al. 1993). Food ingestion represents a substantial cardiovascular challenge, with the magnitude of the cardiovascular responses being directly related to the energy content of the meal ingested. The implications of such findings for those patients with compromised cardiovascular and autonomic function and the elderly are clear. A smaller meal elicits a smaller central and mesenteric response. The impact of such meals in individuals with pathology of the autonomic or cardiovascular systems will be less, hopefully with cardiovascular homeostasis being maintained through more subtle vascular changes which are more likely to be within the capabilities of these patients. Advice to patients with regard to meal composition is more complex. High-carbohydrate meals elicit rapid central and mesenteric responses, and, as mentioned, tend to lower blood pressure in the healthy elderly more than any other meal type. However, high-fat meals, whilst delaying peak cardiovascular responses, result in more prolonged mesenteric hyperaemia than other meals (Moneta et al. 1988; Sidery et al. 1994). Small, mixed meals containing less-readily available, complex carbohydrate are likely to be the least challenging of all meal types to the individuals discussed.

This work was supported by a Project Grant from the Wellcome Trust.

\section{REFERENCES}

Berne, C., Fagius, J. \& Niklasson, F. (1989). Sympathetic response to oral carbohydrate administration: evidence from microclectrode nerve recordings. Joumal of Clinicat Investigation 84, 1403-1409.

Colles, P.. Juneau, M., Grégoir, J., Larivée, L.. Desideri, A. \& Waters, D. (1993). Effect of a standardized meal on the threshold of exercise-induced myocardial ischemia in patients with stable angina. Journal of the American College of Cardiology 21, $1052-1057$.

Cowley, A. J., Fullwood, L. J., Stainer, K., Harrison, E., Muller, F. \& Hampton, J. R. (1991). Post-prandial worsening of angina: all due to changes in cardiac output. British Heart Journal 66, 147-150.

Cowley, A. J., Murphy, D. T. \& Stainer, K. (1986). A non-invasive method for measuring cardiac output: the effect of Christmas lunch. Lancet ii, 1422-1424. 
Dagenais, G. R., Oriol, A. \& Gregor, M. (1966). Haemodynamic effects of carbohydrate and proteins in man: rest and exercise. Journal of Applied Physiology 21, 1157-1162.

de Mey, C., Enteriing, D., Brenel, E. \& Meineke, I. (1987). Postprandial changes in supine and erect heart rate, systemic blood pressure and plasma noradrenaline and renin activity in normal subjects. European Journal of Clinical Pharmacology 32, 471-476.

Donald, D. E. (1983). Splanchnic circulation. In Handbook of Physiology, section 2, part 1. Bethesda: American Physiological Society.

Esler, M., Jennings, G., Korner, P., Willett, I., Dudley, F., Hasking, G., Anderson, W. \& Lambert, G. (1988). Assessment of human sympathetic nervous system activity from measurements of norepinephrine turnover. Hypertension 11, 3-20.

Fagan, T. C., Gourley, L. A., Sawyer, P. R., Lee, J. T., Corneux, C. B., Oexman, M. J. \& Gaffney, T. E. (1982). Cardiovascular effects of a meal : clinical implications. Clinical Research 30, 7A.

Fagan, T. C., Sawyer, P. R., Gourley, L. A., Lee, J. T. \& Gaffney, T. E. (1986). Postprandial alterations in haemodynamics and blood pressure in normal subjects. American Journal of Cardiology 58, 636-641.

Gallen, I. W. \& Macdonald, I. A. (1990). Effect of two methods of hand heating on body temperature, forearm blood flow and deep venous oxygen saturation. American Journal of Physiology 259, E639-E643.

Gill, R.W. (1985). Measurement of blood flow by ultrasound: accuracy and sources of error. Ultrasound in Medicine and Biology 11, 625-641.

Gladstone, S. A. (1935). Cardiac output and related functions under basal and postprandial conditions. Archives of Internal Medicine 55, 533-546.

Greenfield, A. D. M., Whitney, R. J. \& Mowbray, J. F. (1963). Methods for the investigation of peripheral blood flow. British Medical Bulletin 19, 101-109.

Heseltine, D. \& Potter, J. F. (1990). Commentary: postprandial hypotension in elderly people. Age and Ageing 19. $233-235$.

Heseltine, D., Potter, J. F., Hartley, G., Macdonald, I. A. \& James, O. F. W. (1990). Blood pressure, heart rate and neuroendocrine responses to a high carbohydrate and a high fat meal in healthy young subjects. Clinical Science 79, 517-522.

Hinderliter, A. L., Fitzpatrick, M. A., Schork, N. \& Julius, S. (1987). Research utility of non-invasive methods for measurement of cardiac output. Clinical Pharmacology and Therapeutics 41, 419-425.

Kelbaek, H., Munck, O., Christensen, N. J. \& Godtfredsen, J. (1987). Autonomic nervous control of postprandial haemodynamic changes at rest and upright exercise. Journal of Applied Phvsiology 63, 1862-1865.

Kelbaek, H., Munck, O., Christensen, N. J. \& Godtfredsen, J. (1989). Central haemodynamic changes after a meal, British Heart Journal 61, 506-509.

Laasko, M., Edelman, S. V., Brechtel, G. \& Baron, A. D. (1990). Decreased effect of insulin to stimulate skeletal muscle blood flow in obese man. A novel mechanism for insulin resistance. Journal of Clinical Investigation $\mathbf{8 5}$, 1844-1852.

Lipsitz, L. A. \& Fullerton, K. J. (1986). Postprandial blood pressure reduction in healthy elderly. Journal of the American Gerontological Society 34, 267-270.

Lipsitz, L. A., Nyquist, R., Wei, J. Y. \& Rowe, J. W. (1983). Postprandial reduction in blood pressure in the elderly. New England Journal of Medicine 309, 81.

Macdonald, I. A. \& Lake, D. M. (1985). An improved technique for extracting catecholamines from body fluids. Journal of Neuroscience Methods 13, 239-248.

McGuire, E. A. H., Helderman, J. H., Tobin, J. D., Andres, R. \& Bergman, R. (1976). Effects of arterial versus venous sampling on glucose kinetics in man. Journal of Applied Physiology 41, 165-173.

Moneta, G. L., Taylor, D. C., Helton, W. S., Mulholland, M. W. \& Strandness, D. E. Jr (1988). Duplex ultrasound measurement of postprandial intestinal blood fow: effect of meal composition. Gastroenterology 95. $1294-1301$.

Muiesan, G., Sorbini, C. A., Solinas, E., Grassi, V., Casucci, G. \& Pedz, E. (1968). Comparison of CO, rebreathing methods and direct Fick methods for determining cardiac output. Journal of Applied Physiology $\mathbf{2 4}$ 424.429 .

Muller, A. F., Hawkins, M., Batin, P., Evans, S. \& Cowley, A. J. (1992). Food in chronic heart failure: improvement in central haemodynamics but deleterious effects on exercise tolerance. European Heart Journal 13. $1460-1467$

Nakamura, T., Moriyasu, F., Ban, N., Nishida, O., Tamada, T., Kawasaki, T., Sakai, M. \& Uchino, H. (1989). Quantitative measurement of abdominal arterial blood flow using image-directed Doppler ultrasonography: superior mesenteric, splenic, and common hepatic arterial blood flow in normal adults. Journal of Clinical Ultrasound 17, 261-268.

Norryd, C., Dencker, H., Lunderquist, A., Olin, T. \& Tylen, U. (1975). Superior mesenteric blood flow during digestion in man. Acta Chirurgica Scandinavica 141, 197-202.

Potter, J. F., Heseltine, D., Hartley, G., Matthews, J., Macdonald, I. A. \& James, O. F. W. (1989). Effects of meal consumption on the postprandial blood pressure, catecholamine and insulin changes in elderly subjects. Clinical Science 77, 265-272.

Qamar, M. 1.\& Read, A. E. (1988). Effects of ingestion of carbohydrate, fat, protein and water on the mesenteric blood flow in man. Scandinavian Journal of Gastroenterology 23, 26-30. 
Reybrouck, T.\& Fagard, R. (1990). Assessment of cardiac output at rest and during exercise by a carbon dioxide rebreathing method. European Heart Joumal 11, Suppl. 11, 21-25.

Roberts, L. N. \& Breckenridge, A. M. (1986). The reproducibility of limb blood flow measurements in human volunteers at rest and after exercise by using mercury in silastic strain gauge plethysmography under standardized conditions. Clinical Science 70, 635-638.

Rowe, J. W., Young, J. B., Minkaer, K. L., Stevens, A. L., Pallotta, J. \& Landsberg, L. (1981). Effect of insulin and glucose infusions on sympathetic nervous system activity in normal man. Diabetes 30, 219-225.

Rowe, J. W., Young, J. B., Stevens, A., Kilgore, A., Pallotta, J. \& Landsberg, L. (1979). Insulin increases plasma noradrenaline in man independent of changes in blood glucose. Clinical Research 27, 594A.

Rowell, L. B., Brengelmann, G. L., Blackmon, J. R., Bruce, R. A. \& Murray, J. A. (1968). Disparities between aortic and peripheral pulse pressures induced by upright exercise and vasomotor changes in man. Circulation 37, 954-964.

Sidery, M. B., Blackshaw, P. E. \& Macdonald, I. A. (1994). Superior mesenteric artery blood flow and gastric emptying in humans and the differential effects of high fat and high carbohydrate meals. Gut 35, 186-190.

Sidery, M. B., Cowley, A. J. \& Macdonald, I. A. (1993). Cardiovascular responses to high fat and high carbohydrate meals in healthy elderly subjects. Clinical Science 84, 263-270.

Sidery, M. B., Macdonald, I. A., Cowley, A. J. \& Fullwood, L. J. (1990). Cardiovascular responses to high-fat and high-carbohydrate meals in young subjects. American Journal of Physiology 261, H1430-H1436.

Torsdottir, I., Alpsten, M., Andersson, H., Schweizer, T. F., Tölli, H. \& Würsch, P. (1989). Gastric emptying and glycemic response after ingestion of mashed bean or potato flakes in composite meals. American Journal of Clinical Nutrition 50, 1415-1419.

Waaler, B. A., Eriksen, M. \& Janbu, T. (1990). The effect of a meal on cardiac output in man at rest and during moderate exercise. Acta Physiologica Scandinavica 140, 167-173.

Waaler, B. A., Eriksen, M. \& Toska, K. (1991). The effect of meal size on postprandial increase in cardiac output. Acta Physiologica Scandinavica 142, 33-37.

Wallin, B. G., Sundloff, G., Eriksson, B.-M., Dominiak, P., Grobecker, H. \& Lindblad, L. E. (1981). Plasma noradrenaline correlates to sympathetic muscle nerve activity in normotensive man. Acta Physiologica Scandinavica 111, 69-73.

Whitney, R. J. (1953). Measurement of volume changes in human limbs. Journal of Physiology (London) 121, 1-27. 